\title{
Physiological stress and the fitness effects of Mpi genotypes in the acorn barnacle Semibalanus balanoides
}

\author{
Patrick A. Flight*, Shane D. Schoepfer, David M. Rand \\ Department of Ecology and Evolutionary Biology, Brown University, Providence, Rhode Island 02912, USA
}

\begin{abstract}
Balancing selection has been invoked to explain the apparent maintenance of polymorphisms at the mannose-6-phosphate isomerase (Mpi) and glucose-6-phosphate isomerase (Gpi) loci in a diverse array of organisms. However, in many cases the agents of selective stress and the grain size of environmental heterogeneity necessary to preserve genetic variation remain uncertain. In the barnacle Semibalanus balanoides, differing selection regimes have been proposed across the species' range. To test whether or not fitness differences segregate with Mpi and Gpi polymorphisms near the southern range limit, barnacles from Narragansett Bay, Rhode Island, were subjected to physiological challenges in the laboratory. Survivorship was measured in barnacles exposed to an orthogonal combination of salinity, thermal and dietary stresses. Cirral length and genotype frequency shifts at Mpi and Gpi were assessed in low salinity treatments. Mortality from thermal stress was greatly enhanced under low salinity. Across all low salinity treatments there was a nonsignificant trend of decreased fitness associated with the Mpi-SS genotype. Cirral length variation was significantly correlated with Mpi genotypes in a pattern consistent with survivorship data.
\end{abstract}

KEY WORDS: Ecological genetics $\cdot$ Semibalanus balanoides $\cdot$ Balancing selection $\cdot$ Environmental heterogeneity · Latent effects

\section{INTRODUCTION}

Models that describe how genetic variation can be maintained by selection are rarely tested and even less frequently demonstrated in field populations. As a result, empirical examples of balancing selection are lacking despite an abundance of mathematical models (Levene 1953, Maynard Smith 1962, Bulmer 1972, Gillespie 1976, Hedrick et al. 1976). Recent genome scans have discovered that the role of selection in shaping genetic diversity may be more important than previously thought (Begun et al. 2007, Hahn 2008). In marine organisms with long generation times and planktonic dispersal, quantitative genetic methods based on laboratory crosses are rarely feasible. Given these circumstances, ecological inference can be used to select candidate genes for focused analyses. Investi- gations of candidate genes have proven an effective method for uncovering selection at protein variants in the past (Koehn et al. 1976, Watt 1977, Hilbish \& Koehn 1985, Crawford \& Powers 1989, Berry \& Kreitman 1993, Hudson et al. 1994, Katz \& Harrison 1997, Nachman et al. 2003). When studies are based on inferences about the role of particular polymorphisms in pathways of central metabolism, a compelling case can be made for a connection between polymorphism and fitness-associated traits (Clarke 1975, Eanes 1999).

The metabolic enzymes mannose-6-phosphate isomerase (MPI) and glucose-6-phosphate isomerase (GPI) are polymorphic in many invertebrates, and numerous studies have found that genotypic frequencies at these enzyme loci vary with environmental conditions in predictable ways (Watt 1977, McDonald 1987, Holm \& Bourget 1994, Riginos et al. 2002). MPI 
and GPI are commonly polymorphic enzymes in barnacles, and the acorn barnacle Semibalanus balanoides has emerged in the past decade as a model system for testing how balancing selection may act to maintain polymorphism at these loci (Hedgecock 1986, Holm \& Bourget 1994, Schmidt \& Rand 1999, Rand et al. 2002, Véliz et al. 2004). S. balanoides is unique because it is one of few systems where balancing selection has been implicated by static sampling of defined microhabitats, experimental manipulations in the field and laboratory manipulation (Schmidt 2001, Schmidt \& Rand 2001, Brind'Amour et al. 2002). Nevertheless, conflicting results about the nature of selection on metabolic enzymes has led to questions about extending results from one geographic region to other populations over the entire species range. While multiple studies in this system have identified non-neutral patterns at Mpi and Gpi, results vary with respect to the grain size of environmental heterogeneity necessary for balancing selection, as well as the hypothesized agent of selective stress. Genotype specific mortality in barnacle species may result from selective effects preceding or following metamorphosis. The term 'latent effects' has been employed to describe selective pressures that act on the planktonic condition of barnacle nauplii in a way that influences post-settlement fitness (Jarrett \& Pechenik 1997, Hentschel \& Emlet 2000, Pechenik 2006).

In the Damariscotta estuary system in Maine, field sampling, cohort analysis and laboratory manipulation suggest that genotype frequency changes at the $\mathrm{Mpi}$ locus are driven by the heat gradient in intertidal microhabitats on a scale of only a few meters (Schmidt \& Rand 1999). Recruits in this system settle in all microhabitats with approximately equal Mpi genotype frequencies. Following metamorphosis, genotype frequencies diverge between cohorts of juveniles in different thermal environments (Schmidt \& Rand 2001). Furthermore, the shift appears to be tied to an interaction between heat stress and dietary carbohydrates (Schmidt 2001). Despite repeated and predictable shifts in Mpi genotype frequencies over multiple study years in the Damariscotta system, the importance of heat stress in other locations has been questioned (Rand et al. 2002). Studies conducted around the Miramichi River system in New Brunswick, Canada, have not shown the same covariation between heat zonation and genotype frequency. In contrast, studies on Miramichi populations demonstrate that genotype frequencies and Mpi and Gpi loci shift abruptly at a regional scale across the Miramichi estuary (Drouin et al. 2002, Dufresne et al. 2002, Véliz et al. 2004). It may be that genotype frequency shifts are the result of latent effects tied to the carbohydrate composition and productivity of the planktonic community north and south of the estuary, but this remains speculative (Véliz et al. 2004). Out of these 2 loci, the locus primarily correlated with barnacle size also varies with location, as Gpi covaries with size phenotypes in New Brunswick, but Mpi covaries with size in Maine (Schmidt 2001, Véliz et al. 2006a).

In the only study to date on MPI and GPI protein polymorphisms in Narragansett Bay, Rhode Island, results were consistent with both selection at the microhabitat and regional scales, suggesting that both may play an important role in this system (Rand et al. 2002). We set out to perform an explicit test of the hypothesis that thermal stress and metabolic substrates interact to dictate selection at Mpi and Gpi in Semibalanus balanoides collected from Narragansett Bay. Specifically, we examined how controlled exposure to heat, diet and salinity conditions influence mortality patterns in early juvenile barnacles from a single year's settlement. To determine how heat and diet regimes affect selection at metabolic enzymes under conditions of low salinity, we measured genotype frequency changes at Mpi and Gpi. We also recorded cirral length phenotypes. The hypothesis addressed by this design was that Mpi genotypes would be selected by thermal stress under growth conditions rich with mannose substrates, and Gpi genotypes would respond to thermal stress in glucose-rich conditions.

\section{MATERIALS AND METHODS}

Experimental design. To harvest a single year's cohort of barnacles, 118 replicate bluestone settlement plates $(15 \times 15 \mathrm{~cm})$ were immobilized in the low intertidal at the same site in Portsmouth Harbor, Narragansett Bay, RI, in December 2006. We set the plates 3 mo prior to settlement to promote growth of a natural community on the substrate surface. All plates were set on wire mesh frames and anchored at approximately the same height in the low intertidal with steel rebar. Plates were monitored throughout the winter and no plates were lost during the collection phase. Settlement of cyprids began in mid-March and continued into April 2007. On 25 April 2007, near the end of the settlement season, plates were collected from the intertidal and moved to flowing seawater laboratory facilities at the University of Rhode Island, Graduate School of Oceanography campus, Narragansett, RI.

A subset of individuals was collected randomly from 10 of the 118 plates on 25 April, placed on ice and brought back to the laboratory to represent fieldcollected samples for subsequent genetic analysis. The remaining 108 settlement plates were randomized among a total of eighteen 17 l plastic bins and received 
unfiltered, unheated, aerated flowing seawater at an average of $700 \mathrm{ml} \mathrm{min}^{-1}$ under constant light for $24 \mathrm{~d}$ to acclimate to laboratory conditions. During this period water flow was stopped for approximately $4 \mathrm{~h}$ each day and drained from each tank to simulate a diurnal low tide cycle; mortality on the plates was not assayed. Plate position between and within each bin was randomized daily to minimize positional effects. Seawater temperature ranged from $13^{\circ} \mathrm{C}$ at the start of treatment to $18^{\circ} \mathrm{C}$ at the end of experimental exposure. To decrease crowding, barnacles were also culled randomly from plate surfaces to a mean value of approximately 2800 barnacles per treated surface, although crowding remained abundant near plate edges. Replicate plates were partitioned randomly into 12 groups ( $\mathrm{n}=9$ per group) for the exposure treatment. At the beginning of the exposure treatment, barnacles were switched to sand-filtered seawater so that dietary conditions could be tightly controlled. The sand filtration system was designed to remove particulate matter larger than $20 \mu \mathrm{m}$ under optimal conditions, but likely removed particulate matter larger than 20 to $50 \mu \mathrm{m}$ during the treatment period.

Barnacles were exposed to an orthogonal combination of heat stress, diet and salinity conditions for an additional 25 d beginning on 19 May 2007 (Fig. S1 in the supplement, available at www.int-res.com/articles/ suppl/m404p139_app.pdf). A subset of half of the plates $(n=54)$ were exposed to increasingly intense heat stress using a light board during the approximately $4 \mathrm{~h}$ low tide period each day when they were not submerged. Temperature of the heated plates, which determined the exposure of the barnacles to within a single degree (Bertness 1989), was monitored with an infrared thermometer and the heat stress treatment started with a daily maximum of $32^{\circ} \mathrm{C}$. By decreasing the distance between the light source and plates, temperature was increased to a daily maximum of approximately $40^{\circ} \mathrm{C}$ for $5 \mathrm{~d}$ prior to the cessation of treatment. The position of the plates was randomized throughout the heating to homogenize heat stress. Plates that were not exposed to heat remained at room temperature and were randomized daily to control for handling effects. Temperatures above $40^{\circ} \mathrm{C}$ are not unrealistic ecological conditions for the Rhode Island intertidal and Semibalanus balanoides individuals were found on rocks in the field during this same period at temperatures above those used in the laboratory exposure. Following low tide, bins were refilled with water at 2 different salinity levels. The ambient seawater plates were refilled with water at approximately 30 to 33 psu, well within the acceptable limits for $S$. balanoides. The plates under salinity stress received seawater mixed with carbon-filtered freshwater to an average minimum of approximately 18 to $20 \mathrm{psu}$, which is near the lower limit of $S$. balanoides tolerance (Foster 1970, 1987). The bins housing the replicate plates were filled and allowed to overflow for several minutes before flow was stopped, and the water was aerated overnight until the bins were drained at the next day's low tide.

Plates were further divided into 3 groups $(n=36)$ and received 3 different diets. One-third of the treated plates received no dietary supplement beyond the food coming in with the filtered seawater. Incoming particulate matter likely fluctuated throughout the treatment based on external water conditions, but all treated plates received the same incoming water. One-third received a diet supplement of the mannose-rich diatom Phaeodactylum tricornutum ad libitum each day following the low tide period. The final third of the replicate plates received a supplement of the glucose-rich diatom Thalassiosira weissflogii ad libitum each day. P. tricornutum (strain: CCMP1327) was ordered from the Provasoli-Guillard National Center for Culture of Marine Phytoplankton (West Boothbay Harbor, Maine) and grown in sterile culture under conditions of constant light at $18^{\circ} \mathrm{C}$, with standard $\mathrm{F} / 2$ media and sodium metasilicate added. One liter of culture per replicate bin was pulled off a pair of 201 clear carboys daily. T. weissflogii (Instant Algae) was ordered in concentrate from Reed Mariculture. Approximately $4 \mathrm{ml}$ of the concentrated solution was diluted in 11 to inoculate each replicate bin daily. Food availability as a function of barnacle mass was not quantified, but barnacles failed to remove all food from the bins each day, suggesting they were not food-limited.

Phaeodactylum tricornutum was selected for its uniquely high mannose concentration. As much as $46 \%$ of total sugars in this species are mannose. Furthermore, this skewed ratio of carbohydrate composition has been hypothesized as a reason $P$. tricornutum is a poor food source for mariculture (Brown et al. 1997). In contrast, Thalassiosira weissflogii is widely recognized as a rich food source for shellfish aquaculture and the relative percentages of aldoses break down to approximately $66.7 \%$ glucose and $9.57 \%$ mannose (Cowie \& Hedges 1996). These values are susceptible to diatom culture conditions, and the fact that $P$. tricornutum were alive during treatment but $T$. weissflogii was from a stock solution. No quantification of carbohydrate composition was made, but diets were selected to represented extremes in carbohydrate differences for diatoms. The use of diatoms, rather than free sugars, as a carbohydrate source was intended to provide a more realistic diet and to address uncertainty about actual uptake of free sugars by barnacles.

Mortality analysis. Treatments continued with qualitative assessments of mortality until individual plates, under the low salinity heated treatments, displayed 
$>50 \%$ mortality. Upon conclusion of treatment, all plates were photographed, images were analyzed in ImageJ software (http://rsbweb.nih.gov/ij/) and living and dead barnacles were counted in a checkerboard pattern over all 108 plates to assess mortality. Individuals were scored as dead if the outer shell plates were empty or cracked, or if the operculum was open beyond the normal pneumostome gap. Abnormal coloration of the shell was also indicative of mortality, possibly due to microbial colonization of dead tissue. Estimates of mortality should be taken as conservative because dead individuals may have not appeared abnormal in the photograph, and the small number of shells that were completely separated from the plate during treatment was not counted. Large per plate sample sizes should make this analysis robust to these exceptions.

Following treatment, survivors from all low salinity plates were removed from plate surfaces with a dissecting needle and frozen for subsequent analysis. Crowding was much more abundant near plate edges, but survivors were drawn randomly from the plate surface. Given the low mortality observed on the ambient salinity plates, individuals from this treatment were not collected for genotyping. Additional efforts to impose mortality on ambient salinity treatments resulted in a single complete mortality event when thermal stress was increased to approximately $45^{\circ} \mathrm{C}$. As a result, all genetic and phenotypic analyses were conducted on field-collected plates and the low salinity plates exposed to all combinations of diets and heat stress. The low salinity conditions are similar to those experienced by upper Narragansett Bay locations (AM, B1, B2, HF) reported in Rand et al. (2002).

Genotype determination and size measurements. Genetic analysis was performed for Mpi and Gpi. An additional genetic marker on the mitochondrial genome was also assayed (see Table S2 in the supplement at www.int-res.com/articles/suppl/m404p139_ app.pdf). Individual barnacles were dissected in water and homogenized whole prior to electrophoresis. Mpi and Gpi genotypes were scored following standard allozyme electrophoresis procedures described in Schmidt \& Rand (1999), which are based on Hebert \& Beaton (1989). Two common alleles, designated as fast (F) and slow (S), were identified for each locus. Recent molecular analyses showed that a single amino acid change is responsible for the fast-slow electrophoretic shift at Mpi in Semibalanus balanoides (P. A. Flight \& D. M. Rand unpubl. data). Rare alleles in the treated barnacles accounted for $<1 \%$ of all alleles scored and never appeared as homozygotes. All individuals with a rare allele were scored as FS heterozygotes following previous conventions in this system (Schmidt \& Rand 1999, Véliz et al. 2004).
Length of the longest cirral appendage was measured to the nearest $1 / 6 \mathrm{~mm}$ using an ocular micrometer for 1190 individuals from field-collected and low salinity treatment groups. Individuals were selected from plates in the laboratory with high mortalities. Unheated plates were sampled for genetic analysis $13 \mathrm{~d}$ after the heat-treated plates, so the increase in cirral length in this group is due to a combination of low heat stress and additional time for growth. To account for different collecting dates, cirral lengths were also analyzed as genotype-dependent deviations from group means.

Statistical analysis. Hardy-Weinberg equilibrium (HWE) and genotypic linkage disequilibrium were assessed using Fisher exact tests in Stata/SE 10.0 (StataCorp 2007) with the package 'genhw' for pooled totals, as well as for individuals from each treatment condition. Percent mortality data from plate surfaces was logit-transformed to satisfy assumptions of heteroscedasticity in ANOVA analysis. Genotype data were analyzed with a multinomial logistic regression in Stata/SE 10.0, which fits maximum likelihood logits for multiple categorical outcomes. Analyses specified the rare genotypes from each locus as the base outcome and identified log odds for the probability of sampling the alternative genotypes relative to the rare genotype for all treatments. The intercept term in the model corresponds to the natural log of the ratio of the genotype of interest to the base genotype. Treatment effects refer to the change in log odds for each treatment. Specification of the base outcome does not influence statistical significance. Fitness was estimated from genotype data by dividing frequencies following treatments by initial frequencies (Hartl \& Clark 1997). However, these values should be interpreted with caution because they are susceptible to initial genotype frequencies. Cirral length phenotypes were analyzed with linear mixed models using the package 'nlme' in R (Pinheiro et al. 2008, R Development Core Team 2008). Genotypes and treatments were treated as fixed effects and plate identity was used as a random effect in the model.

\section{RESULTS}

\section{Mortality data}

A total of 152286 barnacles were scored from all 108 replicate plates exposed to heat, diet and salinity conditions in the laboratory. Mortality was low on all plates that were not exposed to heat stress, with a plate mean mortality of $3.95 \%$. The treatment conditions explained $>90 \%$ of the variance in logit-transformed mortality data $\left(F_{11,108}=96.69, \mathrm{p}<0.0001\right.$, adjusted $\mathrm{R}^{2}=$ 
0.9077; Table 1, Fig. 1). Individuals exposed to high heat conditions experienced much greater mortality under conditions of low salinity. The effects of diet were also significant; however, dietary conditions only accounted for a small proportion of the variance in plate mortality.

Table 1. Environmental sources of mortality of the acorn barnacle Semibalanus balanoides. ANOVA table of logit-transformed percent mortality on each of 9 replicate plates as a function of treatment groups and interactions (adjusted $\mathrm{R}^{2}=$ 0.9077). The logit transformation was used to satisfy assumptions of heteroscedasticity (Cook-Weisberg test following transformation, $\mathrm{p}=0.2013$ ). Heat, salinity and their interaction explained the majority of the variance in logit-transformed percent mortality. Diet effects on mortality were small but significant

\begin{tabular}{|lrrrr|}
\hline Source & $\begin{array}{c}\text { Partial sum } \\
\text { of squares }\end{array}$ & df & $F$ & $p$ \\
\hline Model & 220.22 & 11 & 96.69 & $<0.0001$ \\
Heat & 173.72 & 1 & 839.04 & $<0.0001$ \\
Salinity & 23.61 & 1 & 114.05 & $<0.0001$ \\
Diet & 2.45 & 2 & 5.91 & 0.0038 \\
Heat $\times$ Salinity & 19.20 & 1 & 92.71 & $<0.0001$ \\
Heat $\times$ Diet & 0.32 & 2 & 0.77 & 0.4664 \\
Salinity $\times$ Diet & 0.34 & 2 & 0.82 & 0.4423 \\
Heat $\times$ Salinity $\times$ Diet & 0.58 & 2 & 1.41 & 0.2503 \\
Residual & 19.88 & 96 & & \\
\hline
\end{tabular}

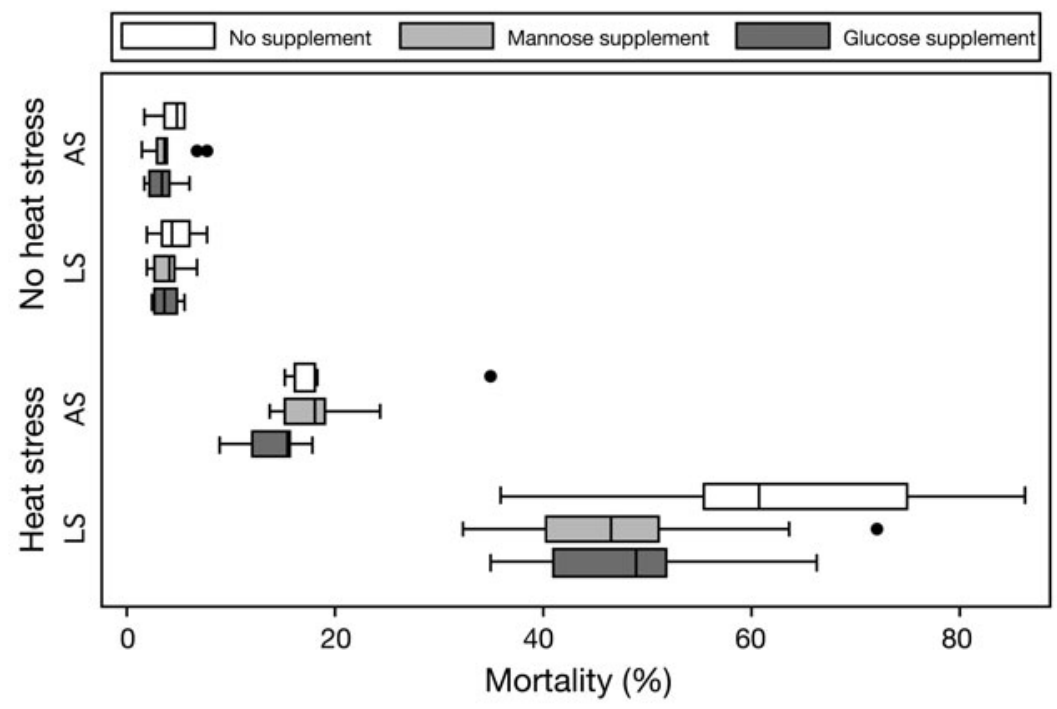

Fig. 1. Semibalanus balanoides. Mortality by treatment category. Mortality estimates are based on percent mortality per plate ( $\mathrm{n}=9$ for each treatment). LS: low salinity (stressful salinity limit); AS: ambient salinity. Box shading corresponds to diet as indicated. Vertical line: median; box: interquartile range (IQR, i.e. 25 th -75 th percentile); whiskers: lowest and highest value falling $<1.5 \times$ IQR above and below 25th and 75th percentile, respectively; dot: outlier

\section{HWE and linkage disequilibrium}

Field-collected individuals were in HWE at both the Mpi and Gpi loci. There was no significant linkage disequilibrium detected between $\mathrm{Mpi}$ and Gpi in any of the treatments using pairwise Fisher exact test comparisons (Table S1 in the supplement). All heat $\times$ diet combinations yielded genotypic frequencies not significantly different from those expected under HWE (Table S1).

\section{Mpi data}

At the Mpi locus, a minimum of 200 individuals were genotyped per treatment combination, and 1591 individuals were typed overall (Table 2). The full model with heat and diet interactions for laboratorytreated plates could not reject neutrality at this locus and showed no significant effect of diet, temperature or the interaction term on the frequency of $\mathrm{Mpi}$ genotypes $\left(\chi^{2}{ }_{10}=8.11, \mathrm{p}=0.6180\right)$. There was a nonsignificant trend of selection against the Mpi-SS homozygote in all laboratory treatments compared to the field-collected samples (Fig. 2). Contrasts between field-collected barnacles and barnacles heat-stressed in the laboratory were significant; however, the model using the field-collected samples, non-heated laboratory plates and heated laboratory plates as predictor variables was not significant overall $\left(\chi_{4}^{2}=6.37, \mathrm{p}=\right.$ 0.1730 ; Table 3$)$. The magnitude of the fitness differences observed was less than previously seen in laboratory exposures (Schmidt 2001) and field collections in Maine and New Brunswick (Schmidt \& Rand 1999, Véliz et al. 2004).

\section{Gpi data}

Similar analyses were conducted at the Gpi locus, and a minimum of 200 individuals were genotyped per treatment combination with 1650 individuals genotyped overall (Table 2, Fig. 2). As with Mpi, the multinomial logistic regression could not rule out that genotypic frequencies behaved neutrally $\left(\chi^{2}{ }_{10}=14.99, \mathrm{p}=\right.$ 0.1325). Analysis of the 3 treatment types, field-collected, non-heated plates and heated plates, was also not significant $\left(\chi^{2}{ }_{4}=6.37, \mathrm{p}=0.1732\right.$; Table 3). 
Table 2. Frequencies of genotypes at Mpi and Gpi loci for acorn barnacles Semibalanus balanoides from field-collected samples and all heat and diet conditions under low salinity. Relative fitness measurements are based on frequencies of field-collected samples. The number of plates indicates the number of replicate plates from which samples of barnacles were drawn to obtain frequency estimates. Reduced fitness values of the Mpi-SS genotypes in all treatments relative to the field collected barnacles are in bold. n/a: not applicable

\begin{tabular}{|c|c|c|c|c|c|c|c|c|}
\hline \multirow{2}{*}{$\begin{array}{l}\text { Mpi genotype } \\
\text { Treatment }\end{array}$} & \multirow{2}{*}{$\begin{array}{l}\text { No. } \\
\text { plates }\end{array}$} & \multirow{2}{*}{$\begin{array}{c}\text { No. } \\
\text { individuals }\end{array}$} & \multicolumn{2}{|c|}{$\longrightarrow$ Mpi-SS } & \multicolumn{2}{|c|}{$\longrightarrow$ Mpi-FS } & \multicolumn{2}{|c|}{ Mpi-FF } \\
\hline & & & Frequency & Fitness & Frequency & Fitness & Frequency & Fitness \\
\hline Field collected & 8 & 216 & 0.1574 & $\mathrm{n} / \mathrm{a}$ & 0.4352 & $\mathrm{n} / \mathrm{a}$ & 0.4074 & $\mathrm{n} / \mathrm{a}$ \\
\hline No heat, no supplement & 7 & 202 & 0.1337 & 0.8494 & 0.4752 & 1.0919 & 0.3911 & 0.9600 \\
\hline Heat, no supplement & 9 & 247 & 0.0972 & 0.6175 & 0.4534 & 1.0418 & 0.4494 & 1.1031 \\
\hline No heat, mannose supplement & 7 & 204 & 0.1471 & 0.9346 & 0.4216 & 0.9688 & 0.4314 & 1.0589 \\
\hline Heat, mannose supplement & 9 & 261 & 0.0881 & 0.5597 & 0.4598 & 1.0565 & 0.4521 & 1.1097 \\
\hline No heat, glucose supplement & 7 & 206 & 0.1262 & 0.8018 & 0.4660 & 1.0708 & 0.4078 & 1.0010 \\
\hline Heat, glucose supplement & 9 & 255 & 0.1216 & 0.7726 & 0.4824 & 1.1085 & 0.3961 & 0.9723 \\
\hline No heat, pooled & 21 & 612 & 0.1356 & 0.8615 & 0.4542 & 1.0437 & 0.4101 & 1.0066 \\
\hline Heat, pooled & 27 & 763 & 0.1022 & 0.6493 & 0.4653 & 1.0692 & 0.4325 & 1.0616 \\
\hline Total & 56 & 1591 & 0.1226 & $\mathrm{n} / \mathrm{a}$ & 0.4569 & n/a & 0.4205 & n/a \\
\hline Gpi genotype & No. & No. & \multicolumn{2}{|c|}{$\longrightarrow$ Gpi-SS $\longrightarrow$} & \multicolumn{2}{|c|}{$\longrightarrow$ Gpi-FS } & \multicolumn{2}{|c|}{$\longrightarrow$ Gpi-FF } \\
\hline Treatment & plates & individuals & Frequency & Fitness & Frequency & Fitness & Frequency & Fitness \\
\hline Field collected & 8 & 256 & 0.4609 & $\mathrm{n} / \mathrm{a}$ & 0.4414 & n/a & 0.0977 & $\mathrm{n} / \mathrm{a}$ \\
\hline No heat, no supplement & 7 & 202 & 0.4406 & 0.9560 & 0.4208 & 0.9533 & 0.1386 & 1.4186 \\
\hline Heat, no supplement & 9 & 251 & 0.5100 & 1.1065 & 0.3904 & 0.8845 & 0.0996 & 1.0194 \\
\hline No heat, mannose supplement & 7 & 207 & 0.4734 & 1.0271 & 0.3961 & 0.8974 & 0.1304 & 1.3347 \\
\hline Heat, mannose supplement & 9 & 261 & 0.4598 & 0.9976 & 0.4751 & 1.0763 & 0.0651 & 0.6663 \\
\hline No heat, glucose supplement & 7 & 213 & 0.5117 & 1.1102 & 0.3662 & 0.8296 & 0.1221 & 1.2497 \\
\hline Heat, glucose supplement & 9 & 260 & 0.4462 & 0.9681 & 0.4385 & 0.9934 & 0.1154 & 1.1812 \\
\hline No heat, pooled & 21 & 622 & 0.4759 & 1.0325 & 0.3939 & 0.8924 & 0.1302 & 1.3327 \\
\hline Heat, pooled & 27 & 772 & 0.4715 & 1.0230 & 0.4352 & 0.9860 & 0.0933 & 0.9550 \\
\hline Total & 56 & 1650 & 0.4715 & $\mathrm{n} / \mathrm{a}$ & 0.4206 & $\mathrm{n} / \mathrm{a}$ & 0.1079 & $\mathrm{n} / \mathrm{a}$ \\
\hline
\end{tabular}

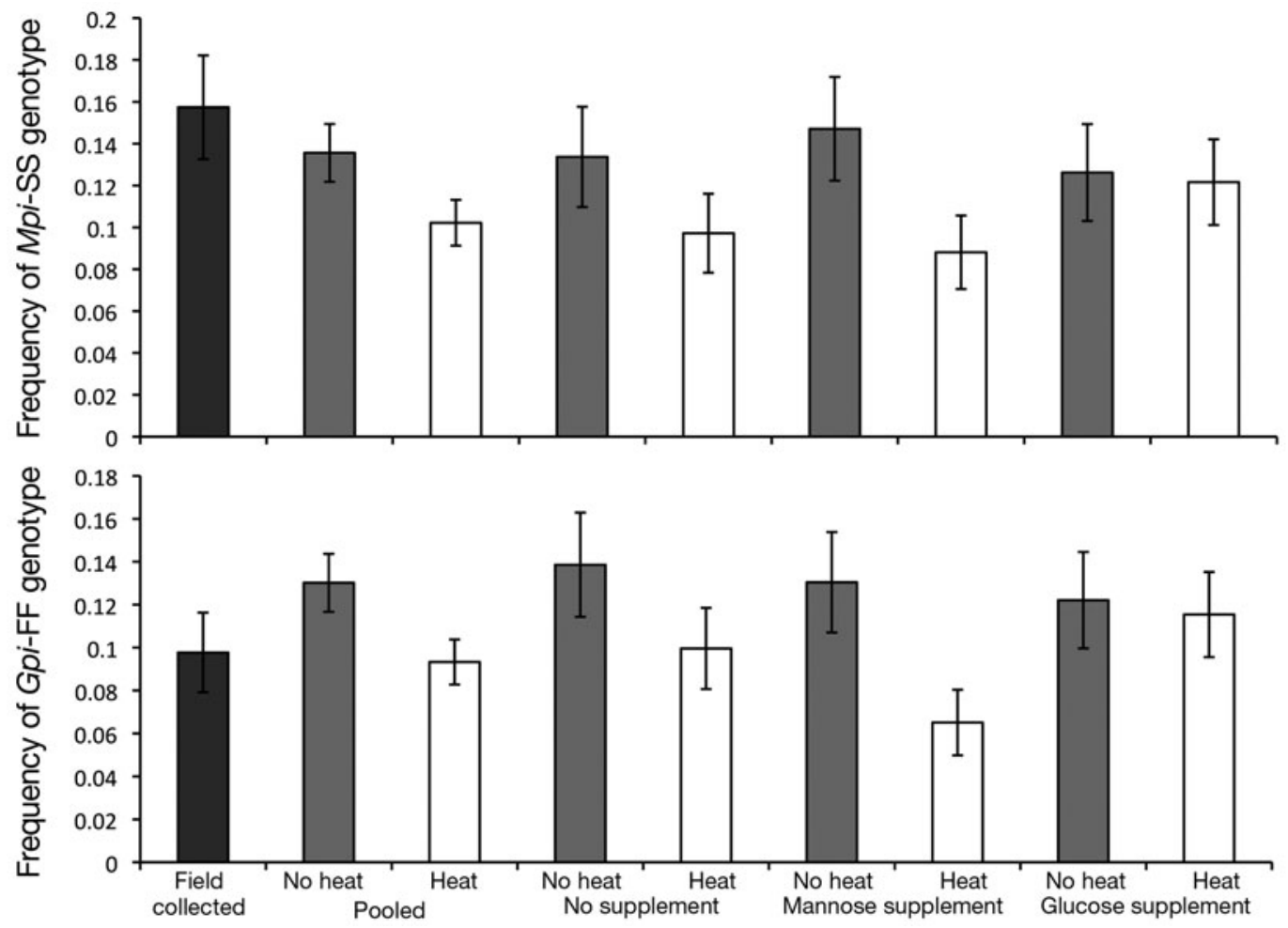

Fig. 2. Semibalanus balanoides. Frequency of Mpi-SS and Gpi-FF genotypes by treatment. Genotype frequency for the rare homozygote at each locus is shown for field-collected samples (dark gray) as well as different diet and heat regimes at low salinity. 
Table 3. Genotype shifts at Mpi and Gpi in the acorn barnacle Semibalanus balanoides. Multinomial logistic regression table with 2 generalized logits specified for the 3 genotypes at each locus. Data for laboratory treatments are pooled across diets. Although individual terms within the Mpi model are significant $\left({ }^{*}\right)$, both models fell below significance overall $\left(M p i: \chi_{4}^{2}=6.37, p=0.1730\right.$; Gpi: $\left.\chi^{2}{ }_{4}=6.37, \mathrm{p}=0.1732\right)$

\begin{tabular}{|c|c|c|c|c|c|c|c|c|}
\hline \multirow{2}{*}{$\begin{array}{l}\text { Mpi locus } \\
\text { Variable }\end{array}$} & \multicolumn{4}{|c|}{ - Logit 1 (FS/SS) } & \multicolumn{4}{|c|}{ - Logit 2 (FF/SS) - } \\
\hline & Coefficient & SE & $\mathrm{z}$ & $\mathrm{p}$ & Coefficient & SE & $\mathrm{z}$ & $\mathrm{p}$ \\
\hline Field collected (intercept) & 1.0169 & 0.2001 & 5.08 & $<0.001$ & 0.9510 & 0.2019 & 4.71 & $<0.001$ \\
\hline Laboratory, non-heated & 0.1918 & 0.2360 & 0.81 & 0.416 & 0.1556 & 0.2383 & 0.65 & 0.514 \\
\hline Laboratory, heated & 0.4985 & 0.2360 & 2.11 & $0.035^{*}$ & 0.4914 & 0.2380 & 2.07 & $0.039^{*}$ \\
\hline \multirow{2}{*}{$\begin{array}{l}\text { Gpi locus } \\
\text { Variable }\end{array}$} & \multicolumn{4}{|c|}{ - Logit 1 (FS/FF)- } & & \multicolumn{3}{|c|}{ - Logit 2 (SS/FF) } \\
\hline & Coefficient & SE & $\mathrm{z}$ & $\mathrm{p}$ & Coefficient & $\mathrm{SE}$ & $\mathrm{z}$ & $\mathrm{p}$ \\
\hline Field collected (intercept) & 1.5518 & 0.2202 & 7.05 & $<0.001$ & 1.5085 & 0.2210 & 6.83 & $<0.001$ \\
\hline Laboratory, non-heated & -0.2559 & 0.2534 & -1.01 & 0.313 & -0.4017 & 0.2555 & -1.57 & 0.116 \\
\hline Laboratory, heated & 0.0687 & 0.2552 & 0.27 & 0.788 & 0.0319 & 0.2563 & 0.12 & 0.901 \\
\hline
\end{tabular}

\section{Phenotypic analysis of cirral length}

Within laboratory-treated plates, diet did not significantly affect barnacle size in any of the treatment groups. Treatment grouping (field versus lab, with or without heat) significantly influenced size and reflected the time at which individuals were collected (Fig. 3). The model which included Mpi genotype and the $M p i \times$ treatment interaction was a significantly better fit to the data than the model treatment alone based on a likelihood ratio test $(\mathrm{L}=19.19$, $\mathrm{df}=6, \mathrm{p}=0.0039$; Table 4). In contrast, the same analysis with Gpi revealed no significant effects on cirral length. The way in which Mpi genotype influenced barnacle size was dependent on treatment type. Individuals from the

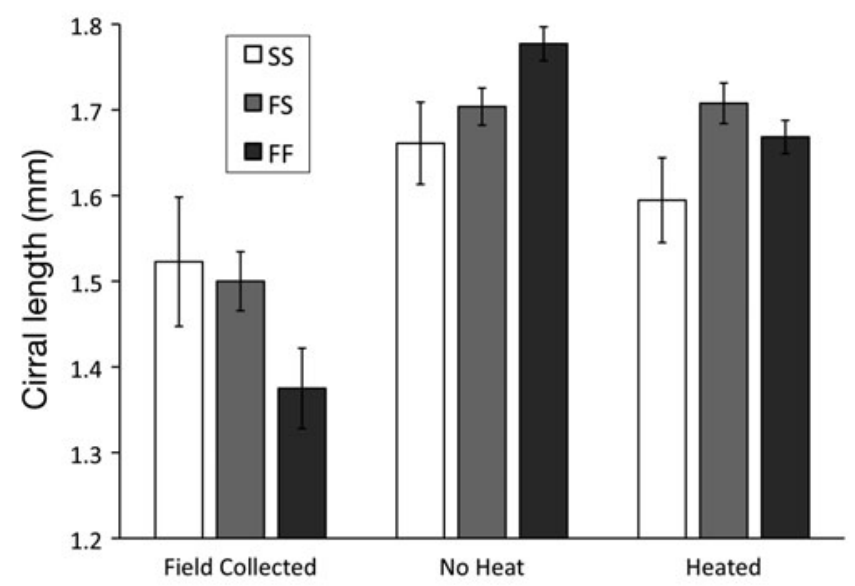

Fig. 3. Semibalanus balanoides. Cirral length as a function of treatment and genotype (F: fast; S: slow). The mean length of the longest cirral appendage $( \pm 1 \mathrm{SE})$ is shown for each $\mathrm{Mpi}$ genotype under each treatment condition. Variable age accounts for the main differences between the 3 groups, but height indicates relative sizes of the different genotypes rare SS homozygote class were the largest in the fieldcollected samples. However, that pattern was reversed in the heat-treated and unheated plate treatments, where the rare homozygotes were the smallest under both conditions (Fig. 4). Mpi genotype and the interaction term between $M p i$ and treatment also significantly improved the fit of the model in an analysis of the laboratory samples alone (no heat versus heated) ( $\mathrm{L}=$ 14.04, df $=4, \mathrm{p}=0.0072$ ).

\section{DISCUSSION}

Studies of selection on key metabolic enzymes usually converge on the problem of flux of substrates through the pathways that are regulated by those enzymes. While allozymes were initially applied in evolutionary genetics as putative random markers, the biochemical assay that enables their use has a potential connection to fitness (Eanes 1999). For MPI and

Table 4. Genotype-environment interaction at Mpi. Linear mixed effect model for the length of the longest cirral appendage as a function of treatment and Mpi genotype in the acorn barnacle Semibalanus balanoides. Data were analyzed with maximum likelihood and modeled with plate identity as a random effect. The highly significant treatment term is unsurprising given the additional time for growth on treated plates. The interaction between treatment and Mpi genotype significantly improves the fit of the model

\begin{tabular}{|lccr|}
\hline Source & df & $F$ & $p$ \\
\hline Intercept & 1,955 & 20721.354 & $<0.0001$ \\
Treatment & 2,28 & 26.921 & $<0.0001$ \\
Mpi genotype & 2,955 & 1.509 & 0.2216 \\
Treatment $\times$ Mpi genotype & 4,955 & 4.057 & 0.0029 \\
\hline
\end{tabular}




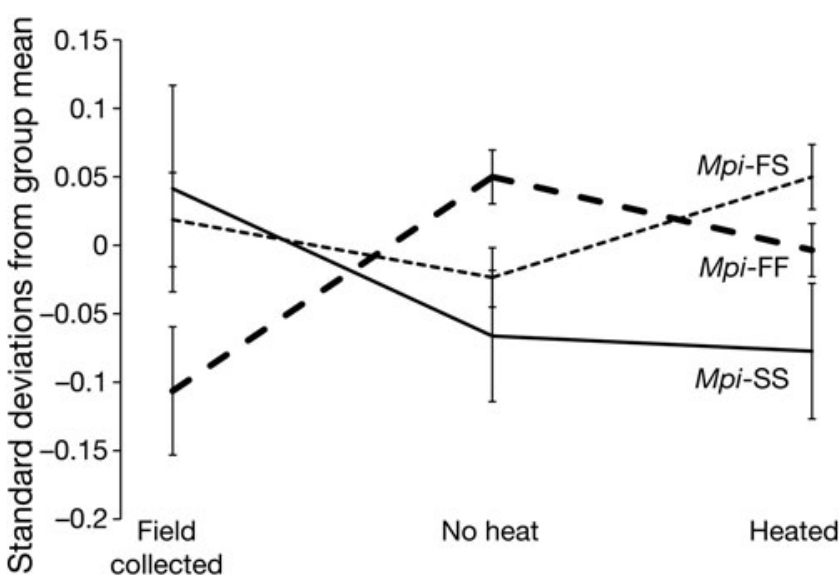

Fig. 4. Semibalanus balanoides. Norms of reaction for $\mathrm{Mpi}$ genotypes. Treatment conditions are indicated on the $\mathrm{x}$-axis. Values are pooled across diets for low salinity in heated and non-heated plates. The Mpi-SS genotype has the largest average size in field-collected plates but is smallest in both laboratory conditions, consistent with the reduced frequency of Mpi-SS in these treatments. Error bars are $\pm 1 \mathrm{SE}$

GPI enzymes in a variety of organisms, there is compelling evidence that allelic variation at each locus is functionally related to the conversion of energy in glucose or mannose into some currency related to fitness. The present study on barnacles set out to test this hypothesis in light of conflicting data indicating that these 2 loci behave quite differently under different geographic and environmental settings (Schmidt \& Rand 1999, 2001, Rand et al. 2002, Véliz et al. 2004, 2006b).

Across all low salinity treatments we found a nonsignificant trend of selection against the Mpi-SS genotype independent of diet, and a significant correlation between cirral length and Mpi. There were no significant effects associated with Gpi. If selection acts to maintain variation at Mpi it must do so through the interaction of wide gene flow and variable selection at multiple spatial scales (Brown et al. 2001, Rand et al. 2002, Véliz et al. 2004). In the broader context of selection on enzyme polymorphisms, our results bear on the pattern that selection at Mpi seems more common on phytoplankton-feeding marine invertebrates and Gpi selection dominates in nectar- and cellulose-feeding insects (cf. Schmidt \& Rand 1999).

\section{Mortality data}

Through analysis of mortality, we found that heat and salinity stress interact to shape barnacle mortality patterns, indicating that barnacles living near the lower limit of salinity tolerance are much more susceptible to thermal stress than those living in full seawater.
Previous studies have indicated that Semibalanus balanoides is susceptible to salinities below 17 psu (Foster 1970); however, we found that salinity effects were dependent on another stress, in this case heat. Results of the present study suggest that heat and salinity act non-additively in barnacles, as low salinity did not induce mortality above the baseline in the absence of heat. This result could have implications for climate change, as mortality in low-salinity areas may be enhanced under warming conditions. As predicted, the diet also significantly influenced survivorship, with individuals that received only filtered seawater dying at a higher rate than those receiving a diatom supplement.

\section{Genetic effects}

Although a trend of selection against the rare $\mathrm{Mpi}$ SS genotype was observed, this shift occurred across all low-salinity conditions and was only significant as a contrast between individuals from heated plates and the field. The data demonstrate that heat stress is lethal, but do not allow us to conclude that heat treatments such as those imposed in these experiments are the primary agent of selection at Mpi in the system. Barnacles may have been weakened by genotypespecific latent effects or selective agents prior to laboratory conditioning that decreased their initial fitness. Therefore, heat stress may exacerbate a weakened state brought on by another cause. Furthermore, shifts in the frequency of $\mathrm{Mpi}$-SS were diet independent, suggesting carbohydrate substrates did not influence selection. It is noteworthy that these experiments are consistent with studies in Maine, where the shifts in frequency at the Gpi locus were not significant (cf. Schmidt 2001).

Although fitness differences were small compared to previous studies, phenotypic measurements of cirral length significantly segregated with Mpi genotype and further supported the conclusion that Mpi-SS was a weak genotype in our laboratory treatments. These results support those of Véliz et al. (2006a), who suggested a 2-stage selection process consisting of genotype-specific mortality shortly after settlement, followed by a genotype-specific growth association in later life. Opercular width is a classic measurement of barnacle size; however, cirral length is expected to be an important fitness trait due to its relationship with resource acquisition in filter feeding. Previous links between size and genotype have been documented at both the Mpi and Gpi loci (Schmidt 2001, Véliz et al. 2006a). In the present study, Mpi-SS homozygotes represented the largest class of individuals among fieldcollected barnacles in the first 2 mo after settlement. 
However, by the end of our laboratory culture experiments, Mpi-SS individuals were the smallest in all groups. These data imply that the FF and FS genotypes experienced a higher growth rate throughout the course of their time in the laboratory, which would be consistent with the higher survival probabilities of those genotypes. Previous studies examining cirral length variation have shown that the trait is highly plastic and up to $99 \%$ of its variance can be explained by wave exposure and flow regimes in other thoracian barnacles (Arsenault et al. 2001, Marchinko 2003). Given that our barnacles were held under common garden conditions and randomized daily with respect to position in the bins, it is unlikely that differences in cirral length among genotypes could be explained by spurious phenotypic plasticity. While these data alone are not sufficient to demonstrate balancing selection at Mpi in Rhode Island, they do show the crossing reaction norms that are an important aspect of marginal overdominance models for the maintenance of genetic polymorphism (Fig. 4). Consistent with earlier studies in Maine (Schmidt \& Rand 1999,2001, Schmidt et al. 2000), the beneficial effects of the Mpi-SS genotype were seen in the most physiologically benign environment (early settlers in the field), and the deleterious effects of this genotype were evident under non-ideal conditions (lab culture).

\section{Alternative interpretations}

The observed patterns could be a result of a cohort containing individuals from a series of settlement events that had different frequencies for the Mpi genotype and variable fitness at settlement independent of Mpi. Under this scenario, what may be seen as selection on a specific allele at Mpi could in fact be selection on a cohort of individuals with a high frequency of that allele. While plausible, this explanation seems unlikely for 2 reasons: first, settlers were observed to be in HWE, which would be unlikely if the cohort represented settlers with different allele frequencies; and second, no linkage disequilibrium was observed in settlers or any treatment combination between $M p i$ and Gpi genotypes (Table S1). This result at least suggests that the settler pool was not a mixture of individuals from parental populations with very different allele frequencies. Another potential reason for discrepancies with previous studies may be that the divergence of genotype frequencies occurs very early after settlement (Schmidt \& Rand 2001, Veliz et al. 2004). The barnacles used in the present study would still be classified as early juveniles given the time at collection, but more pronounced shifts in genotype frequencies might have been evident if individuals were exposed imme- diately following metamorphosis. It is unfortunate that ambient salinity treated individuals were lost in the experiment, precluding estimates of salinity effects on genotype-associated fitness. We cannot eliminate the possibility that the stressful salinity regime altered selective stress against loci predominantly influenced by the thermal environment.

Allozyme analysis provides prima facie evidence for amino acid polymorphism, but lacks the information of DNA sequence variation. One possible mechanism for the contrasting patterns of selection at multiple sites is cryptic allelic variation within allozyme classes (Eanes 1999, Wheat et al. 2006, Orsini et al. 2009). Variable levels of linkage disequilibrium between the nucleotide sites under selection and allozyme charge change could account for observed differences in intensity of selection across the species range. Preliminary results implicate a single amino acid substitution as responsible for the 2 allozyme alleles, suggesting that geographic variation in selection is due to local differences in ecological pressures rather than selection on cryptic amino acid variants among allozymes (P. A. Flight \& D. M. Rand unpubl. data). A complete analysis of nucleotide polymorphism and linkage disequilibrium across the Mpi genomic region is underway to address selection at specific nucleotides, and will be reported elsewhere.

In conclusion, conflicting selection regimes from different geographic ranges are not unexpected because it is naïve to assume that a single mechanism of selection will apply in all ecological settings. In Semibalanus balanoides, multiple scales of environmental heterogeneity may be necessary to maintain, or at least prolong, the existence of multiallelic states at metabolic loci. Results from the present study showed a trend of selection at Mpi in barnacles from Narragansett Bay, RI, that is consistent with size phenotype variation. However, while functional assays have been a critical component of integrative studies of molecular polymorphisms for decades, functional assays alone are only one mechanism to test for the existence of selection. While the precise control afforded by a laboratory setting is attractive, replicating the ecological conditions relevant to historical selection in a filterfeeding invertebrate is challenging. Ultimately, sequence variation at the Mpi and Gpi loci in S. balanoides will need to be integrated with functional experiments to establish whether selection has operated over longer evolutionary time scales.

Acknowledgements. We acknowledge the helpful assistance of E. Baker and the staff and faculty of the University of Rhode Island Graduate School of Oceanography in Narragansett, RI, where the barnacles were held. We also thank P. Schmidt for helpful conversations. P.A.F. was supported by an Experimen- 
tal Program to Stimulate Competitive Research (EPSCoR) Graduate Research Fellowship and S.D.S. was supported by a Summer Undergraduate Research Fellowship from the Rhode Island NSF EPSCoR program. Additional support was provided by NSF grant DEB-0108500 to D.M.R.

\section{LITERATURE CITED}

Arsenault DJ, Marchinko KB, Palmer AR (2001) Precise tuning of barnacle leg length to coastal wave action. Proc $\mathrm{R}$ Soc Lond B Biol Sci 268:2149-2154

Begun DJ, Holloway AK, Stevens K, Hillier LW and others (2007) Population genomics: whole-genome analysis of polymorphism and divergence in Drosophila simulans. PLoS Biol 5:e310, doi:10.1371/journal.pbio.0050310

Berry A, Kreitman M (1993) Molecular analysis of an allozyme cline: alcohol dehydrogenase in Drosophila melanogaster on the east coast of North America. Genetics 134:869-893

Bertness MD (1989) Intraspecific competition and facilitation in a northern acorn barnacle population. Ecology 70: $257-268$

Brind'Amour A, Bourget E, Tremblay R (2002) Fecundity, growth rate and survivorship at the interface between two contiguous genetically distinct groups of Semibalanus balanoides. Mar Ecol Prog Ser 229:173-184

Brown MR, Jeffrey SW, Volkman JK, Dunstan GA (1997) Nutritional properties of microalgae for mariculture. Aquaculture 151:315-331

Brown AF, Kann LM, Rand DM (2001) Gene flow versus local adaptation in the northern acorn barnacle, Semibalanus balanoides: insights from mitochondrial DNA variation. Evolution 55:1972-1979

Bulmer MG (1972) Multiple niche polymorphism. Am Nat 106:254-257

Clarke B (1975) The contribution of ecological genetics to evolutionary theory: detecting the direct effects of natural selection on particular polymorphic loci. Genetics 79(Suppl):101-113

Cowie GL, Hedges JI (1996) Digestion and alteration of the biochemical constituents of a diatom (Thalassiosira weissflogii) ingested by an herbivorous zooplankton (Calanus pacificus). Limnol Oceanogr 41:581-594

Crawford DL, Powers DA (1989) Molecular basis of evolutionary adaptation at the lactate dehydrogenase-B locus in the fish Fundulus heteroclitus. Proc Natl Acad Sci USA 86: 9365-9369

- Drouin CA, Bourget E, Tremblay R (2002) Larval transport processes of barnacle larvae in the vicinity of the interface between two genetically different populations of Semibalanus balanoides. Mar Ecol Prog Ser 229:165-172

Dufresne F, Bourget E, Bernatchez L (2002) Differential patterns of spatial divergence in microsatellite and allozyme alleles: further evidence for locus-specific selection in the acorn barnacle, Semibalanus balanoides? Mol Ecol 11: $113-123$

Eanes WF (1999) Analysis of selection on enzyme polymorphisms. Annu Rev Ecol Syst 30:301-326

Foster BA (1970) Responses and acclimation to salinity in the adults of some balanomorph barnacles. Philos Trans R Soc Lond B Biol Sci 256:377-400

Foster BA (1987) Barnacle ecology and adaptation. In: Southward AJ, Crisp DJ (eds) Crustacean issues, Vol 5: barnacle biology. Chapman \& Hall, London, p 113-134

Gillespie JH (1976) A general model to account for enzyme variation in natural populations. II. Characterization of the fitness function. Am Nat 110:809-821
Hahn MW (2008) Toward a selection theory of molecular evolution. Evolution 62:255-265

Hartl DL, Clark AG (1997) Principles of population genetics, 3rd edn. Sinauer Associates, Sunderland, MA

Hebert P, Beaton M (1989) Methodologies for allozyme analysis using cellulose acetate electrophoresis: a practical handbook. Helena Laboratories, Beaumont, TX

Hedgecock D (1986) Is gene flow from pelagic larval dispersal important in the adaptation and evolution of marine invertebrates? Bull Mar Sci 39:550-564

Hedrick PW, Ginevan ME, Ewing EP (1976) Genetic polymorphisms in heterogeneous environments. Annu Rev Ecol Syst 7:1-32

Hentschel BT, Emlet RB (2000) Metamorphosis of barnacle nauplii: effects of food variability and a comparison with amphibian models. Ecology 81:3495-3508

Hilbish TJ, Koehn RK (1985) The physiological basis of natural selection at the Lap locus. Evolution 39:1302-1317

Holm ER, Bourget E (1994) Selection and population genetic structure of the barnacle Semibalanus balanoides in the northwest Atlantic and Gulf of St. Lawrence. Mar Ecol Prog Ser 113:247-256

> Hudson RR, Bailey K, Skarecky D, Kwiatowski J (1994) Evidence for positive selection in the superoxide dismutase (Sod) region of Drosophila melanogaster. Genetics 136: $1329-1340$

Jarrett JN, Pechenik JA (1997) Temporal variation in cyprid quality and juvenile growth capacity for an intertidal barnacle. Ecology 78:1262-1265

Katz LA, Harrison RG (1997) Balancing selection on electrophoretic variation of phosphoglucose isomerase in two species of field cricket: Gryllus veletis and Gryllus pennsylvanicus. Genetics 147:609-621

Koehn R, Milkman R, Mitton J (1976) Population genetics of marine pelecypods. IV. Selection, migration and genetic differentiation in blue mussel Mytilus edulis. Evolution 30: $2-32$

> Levene H (1953) Genetic equilibrium when more than one ecological niche is available. Am Nat 87:331

Marchinko KB (2003) Dramatic phenotypic plasticity in barnacle legs, (Balanus glandula Darwin): magnitude, age dependence and speed of response. Evolution 57: $1281-1290$

Maynard Smith J (1962) Disruptive selection, polymorphism, and sympatric speciation. Nature 195:60-62

> McDonald JH (1987) Repeated geographic variation at three enzyme loci in the amphipod Platorchestia platensis. Evolution 41:438-441

Nachman MW, Hoekstra HE, D'Agostino SL (2003) The genetic basis of adaptive melanism in pocket mice. Proc Natl Acad Sci USA 100:5268-5273

Orsini L, Wheat CW, Haag CR, Kvist J, Frilander MJ, Hanski I (2009) Fitness differences associated with the Pgi SNP genotypes in the Glanville fritillary butterfly (Melitaea cinxia). J Evol Biol 22:367-375

> Pechenik JA (2006) Larval experience and latent effects: metamorphosis is not a new beginning. Integr Comp Biol 46:323-333

Pinheiro J, Bates D, DebRoy S, Sarkar D, R Core Team (2008) nlme: linear and nonlinear mixed effects models. R package version 3.1-90, R Foundation for Statistical Computing, Vienna

R Development Core Team (2008) R: a language and environment for statistical computing. R Foundation for Statistical Computing, Vienna, available at www.R-project.org

> Rand DM, Spaeth PS, Sackton TB, Schmidt PS (2002) Ecological genetics of Mpi and Gpi polymorphisms in the acorn 
barnacle and the spatial scale of neutral and non-neutral variation. Integr Comp Biol 42:825-836

Riginos C, Sukhdeo K, Cunningham CW (2002) Evidence for selection at multiple allozyme loci across a mussel hybrid zone. Mol Biol Evol 19:347-351

Schmidt PS (2001) The effects of diet and physiological stress on the evolutionary dynamics of an enzyme polymorphism. Proc R Soc Lond B Biol Sci 268:9-14

Schmidt PS, Rand DM (1999) Intertidal microhabitat and selection at Mpi: interlocus contrasts in the northern acorn barnacle, Semibalanus balanoides. Evolution 53:135-146

Schmidt PS, Rand DM (2001) Adaptive maintenance of genetic polymorphism in an intertidal barnacle: habitatand life-stage-specific survivorship of Mpi genotypes. Evolution 55:1336-1344

Schmidt PS, Bertness MD, Rand DM (2000) Environmental heterogeneity and balancing selection in the acorn barnacle Semibalanus balanoides. Proc R Soc Lond B Biol Sci 267:379-384

StataCorp (2007) Stata statistical software: release 10. Stata-

Editorial responsibility: Hans Heinrich Janssen,

Oldendorf/Luhe, Germany
Corp, College Station, TX

> Véliz D, Bourget E, Bernatchez L (2004) Regional variation in the spatial scale of selection at $M P I^{*}$ and $G P I^{*}$ in the acorn barnacle Semibalanus balanoides (Crustacea). J Evol Biol 17:953-966

Véliz D, Bourget E, Bernatchez L (2006a) Field evidence for an association between growth and protein polymorphism in the acorn barnacle Semibalanus balanoides. Mar Ecol Prog Ser 308:197-206

Véliz D, Duchesne P, Bourget E, Bernatchez L (2006b) Stable genetic polymorphism in heterogeneous environments: balance between asymmetrical dispersal and selection in the acorn barnacle. J Evol Biol 19:589-599

> Watt WB (1977) Adaptation at specific loci. I. Natural selection on the phosphoglucose isomerase of Colias butterflies: biochemical and population aspects. Genetics 87:177-194

Wheat CW, Watt WB, Pollock DD, Schulte PM (2006) From DNA to fitness differences: sequences and structures of adaptive variants of Colias phophoglucose isomerase (PGI). Mol Biol Evol 23:499-512

Submitted: August 10, 2009; Accepted: January 21, 2010 Proofs received from author(s): March 15, 2010 